Discussion Paper No. 04-06

ICT, Innovation and

Business Performance in Services:

Evidence for

Germany and the Netherlands

Thomas Hempell, George van Leeuwen and

Henry van der Wiel

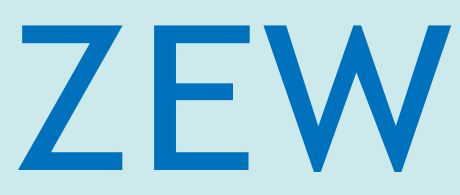

Zentrum für Europäische Wirtschaftsforschung $\mathrm{GmbH}$

Centre for European

Economic Research 


\title{
Discussion Paper No. 04-06 \\ ICT, Innovation and Business Performance in Services: Evidence for Germany and the Netherlands
}

\author{
Thomas Hempell, George van Leeuwen and \\ Henry van der Wiel
}

Download this ZEW Discussion Paper from our ftp server:

\author{
ftp://ftp.zew.de/pub/zew-docs/dp/dp0406.pdf
}

Die Discussion Papers dienen einer möglichst schnellen Verbreitung von neueren Forschungsarbeiten des ZEW. Die Beiträge liegen in alleiniger Verantwortung der Autoren und stellen nicht notwendigerweise die Meinung des ZEW dar.

Discussion Papers are intended to make results of ZEW research promptly available to other economists in order to encourage discussion and suggestions for revisions. The authors are solely responsible for the contents which do not necessarily represent the opinion of the ZEW. 


\section{Non-technical summary}

Information and communication technologies (ICT) have been diffusing rapidly in the industrialised economies during the last decades and are applied for a large variety of purposes. For example, ICT are used to facilitate communication, to easily store and process information, to automate business processes, or to widen the access to information via the Internet. By its rapid diffusion and its various uses, ICT have been compared to other great innovations in the past like the invention of the steam engine or of electricity. These inventions are also designated as general purpose technologies (GPT) since they are suited to be adopted by a wide range of industries and thereby to unfold a sustained impact on the economy.

Apart from the ongoing technological progress within the ICT-producing sector, ICTs have opened a variety of innovation potentials also in a variety of applying sectors. For example, the use of ICT enables firms to restructure their organisations (like flattening of hierarchies and delegating responsibilities), to re-engineer business processes (like introducing just-intime management or engaging in E-commerce) and to develop completely new products (e.g. software or online services). These complementary innovations often involve high additional expenses, such as for reorganisations and for training workers.

In this paper, we analyse the importance of ICT capital deepening and innovation for productivity empirically using panel data for German and Dutch firms in services. We employ a model that takes into account the conjecture that innovation and ICT use are complementary. The results show that the contribution of ICT capital deepening is raised when firms combine ICT use and technological innovations on a more permanent basis. Moreover, the joint impact of ICT use and permanent technological innovation on productivity appears to be of the same order of magnitude in the two countries. Nevertheless, the results found for a direct impact of innovation on multi-factor productivity seems to be more robust for Germany than for the Netherlands. 


\title{
ICT, Innovation and Business Performance in Services: Evidence for Germany and the Netherlands
}

\author{
by \\ Thomas Hempell*, George van Leeuwen ${ }^{\S}$, and Henry van der Wiel
}

\begin{abstract}
Using panel data for German and Dutch firms from the services sector, this paper analyses the importance of ICT capital deepening and innovation for productivity. We employ a model that takes into account that innovation and ICT use may be complementary. The results show that the contribution of ICT capital deepening is raised when firms combine ICT use and technological innovations on a more permanent basis. Moreover, the joint impact of ICT use and permanent technological innovation on productivity appears to be of the same order of magnitude in the two countries. However, the direct impacts of innovation on multi-factor productivity seems to be more robust for Germany than for the Netherlands.
\end{abstract}

Keywords: Productivity, Information and Communication Technologies, Innovation, Services, Panel Data

JEL-Classification: C 23, D 24, L 80, O 32

\footnotetext{
* Centre for European Economic Research (ZEW), Research Group of Information and Communication Technologies. Postal Address: L 7, 1, 68161 Mannheim, email: hempell@zew.de, Tel. +49 -621 1235-233.

The contribution by Thomas Hempell was written as part of the research project "Productivity and Spillover Effects from ICT as a General Purpose Technology" commissioned by the Landesstiftung Baden-Württemberg foundation.

${ }^{\S}$ CPB Netherlands Bureau for Economic Policy Analysis, Project group ICT \& Productivity, e-mail gvl@cpb.nl. " CPB Netherlands Bureau for Economic Policy Analysis, Project group ICT \& Productivity, e-mail hvdw@cpb.nl.
} 


\section{Introduction}

During the last decades, information and communication technologies (ICT) have been diffusing rapidly in industrialised economies. The main forces behind this success story of ICT have been the sustained technological progress in the ICT sector combined with continuously falling prices for computers and networks that attracted more and more firms to invest in these new technologies. However, falling prices are only one part of the story. Most ICT applications can be applied for a large variety of purposes. For example, ICT are used to facilitate communication, to easily store and process information, to automate business processes, or to widen the access to information via the World Wide Web. This broad spectrum of applications has helped ICT to diffuse in practically all sectors of the economy.

This paper focuses on the importance of co-innovation for the adoption of ICT. Although a variety of anecdotal evidence and case studies that point to the crucial role of innovations for a successful implementation of ICT exist, ${ }^{1}$ quantitative studies on the topic are scarce. ${ }^{2}$ In particular, to the best of our knowledge, no contribution in the economic literature on ICT so far has investigated the complementary role of innovations econometrically for more than one country. With this paper, we aim to fill this gap drawing on structurally very similar data from the Community Innovation Survey (CIS) for Germany and the Netherlands.

By its various uses, ICT have been compared to other great innovations in the past like the invention of the steam engine or of electricity. ${ }^{3}$ These inventions are also designated as general purpose technologies (GPT) since they are suited to be adopted by a wide range of industries and thereby to unfold a sustained impact on the economy. Moreover GPT entail a varied potential for technological improvements and a broad scope for innovational complementarities. ${ }^{4}$ The innovation of the microprocessor, on which ICT are crucially based, has initiated series of further innovations like the development of mainframes, personal computers and electronic networks. This development has led to continued productivity gains within the ICT producing industries.

Moreover, and maybe most importantly, ICTs have opened a variety of innovation potentials also in a variety of sectors outside the ICT producing industries. For example, the use of ICT

\footnotetext{
${ }^{1}$ See, e.g., Brynjolfsson and Hitt (2000) for a review.

${ }^{2}$ Exceptions are studies by Licht and Moch (1999) and Hempell (2002a), which focus on the role of product and process innovation in German service firms, as well as studies by Bresnahan et al. (2002) and Brynjolfsson, Hitt and Yang (2002) which analyse complementarities between ICT use and organizational changes.

${ }^{3}$ See David (1991).

${ }^{4}$ See Bresnahan and Traijtenberg (1995).
} 
enables firms to restructure their organisations (like flattening hierarchies and delegation of responsibilities), to re-engineer business processes (like introducing just-in-time management or engaging in e-commerce) and to develop completely new products (e.g. software and consultancies). These complementary measures often involve high additional expenses, such as for reorganisations and for training workers. While some studies based on firm-level evidence and case studies have argued that these co innovations together with an upgrading of skills may entail substantial potentials for firms to raise their productivity, ${ }^{5}$ analyses at the industry level have failed to quantitatively detect such innovational spillovers. ${ }^{6}$

Even though computers are practically everywhere today, the degree of ICT adoption varies substantially between countries and even within sectors. In the two countries this study is focussed on, Germany and the Netherlands, differences are particularly pronounced. The share of expenditures on ICT in gross domestic product in 2002 amounts to $7,8 \%$ in the Netherlands as compared to only $6,4 \%$ in Germany. ${ }^{7}$ These differences in openness for ICT can only partially be explained by structural differences of the economies. ${ }^{8}$ Moreover, the adoption of ICT and its applications also varies strongly between firms within industries and countries. ${ }^{9}$ These differences at the firm-level point to the conjecture that the productivity gains from ICT depend on the individual knowledge base and innovative activities that differ substantially between individual businesses. ${ }^{10}$ In industry figures, these differences between firms are aggregated out, such that innovational spillovers are much more likely to be detected using firm-level data.

ICT adoption is generally most advanced in the service sector. ${ }^{11}$ Moreover, business-related services have been the most important driver of economic growth in industrialised countries. ${ }^{12}$ Despite this key role of services, most existing studies that analyse the productivity impacts of ICT have focussed their attention on manufacturing. By contrast, the focus of the empirical analysis conducted in this paper is on business-related services and distribution services.

For both Germany and the Netherlands, we can make use of longitudinal data for a large number of firms. These panel data allow us to take important methodological issues into account. For example, well-managed firms tend to be more productive and to invest in ICT

\footnotetext{
${ }^{5}$ See, e.g., Bresnahan and Greenstein (1996) and Bresnahan et al. (2002).

${ }^{6}$ Sectoral studies by Stiroh (2002) and Van der Wiel (2001a) find no clear evidence that ICT capital and TFP growth be correlated significantly in the U.S. and the Netherlands respectively.

${ }^{7}$ See EITO (2003).

${ }^{8}$ See van Ark et al. (2002).

${ }^{9}$ See, e.g., Bertschek and Fryges (2002) and Hollenstein (2002).

${ }^{10}$ See Bresnahan and Greenstein (1996), Bresnahan et al. (2002) and Hempell (2002a).

${ }^{11}$ See OECD (2000a).
} 
more intensively. ${ }^{13}$ If such firm-specific effects are not taken into account properly, quantitative analyses may come up with biased results and misleading conclusions. Moreover, the two-country approach allows us to distinguish between links between innovation and ICT usage that are common in both countries on the one hand, and those links that are more likely to result from country-specific environments on the other. Our results show that ICT capital deepening raises productivity and that the productivity improvements are more pronounced when ICT use is combined with a more permanent innovation strategy.

The paper is organised as follows. In the following part, we set out the theoretical background and the empirical model. In section three, we describe the data sources for both Germany and the Netherlands with special attention to the similarities and differences. We then present and compare the empirical results for both countries in section four and discuss the results with special attention to the potentially underlying economic sources. Section five concludes with some final remarks.

\section{Theoretical Background and Empirical Model}

One of the big puzzles about ICT is to explain why firms and countries differ so widely in their ability to make productive use of the potentials entailed in these new technologies. While there exists broad evidence that the diffusion of ICT has led to substantial increases in labour productivity throughout the U.S. economy, results for European countries are rather mixed. ${ }^{14}$ Similarly, the adoption of ICT and its applications vary largely between firms within the same industry. ${ }^{15}$ This heterogeneity has led researchers to explore to what extent the benefits from ICT depend on particular firm characteristics and strategies. In this section we summarise the results obtained on this topic in earlier studies and then discuss an empirical model that is used to investigate the relationship between ICT productivity and complementary innovations.

\subsection{Earlier studies}

Various theoretical and empirical studies have focussed on the specific relevance of innovations and organisational changes involved by applications of ICT within firms. Bresnahan and Greenstein (1996) argue that co-inventions in ICT-using firms involve high adjustment costs and uncertainties that may differ substantially between firms. Similarly,

\footnotetext{
${ }^{12}$ See OECD (2000b).

${ }^{13}$ See Brynjolfsson and Hitt (1995) and Hempell (2000b).

${ }^{14}$ See, e.g., Colecchia and Schreyer (2001), van Ark (2001), van der Wiel (2001a).
} 
Brynjolfsson and Hitt (2000) point out that there are large costs and complementary efforts, e.g. due to complementary organisational changes, that are entailed by an efficient implementation of ICT. These adjustment costs often exceed the costs of ICT investments and may help explain the apparent excess returns that various empirical studies have found for ICT investments. Bresnahan et al. (2002) and Brynjolfsson, Hitt and Yang (2002) report evidence that the usage of ICT involves whole clusters of complementary efforts such as organisational changes, innovations and an upgrading of the skills of the workforce simultaneously. The difficulty to introduce such clusters of arrangements simultaneously may explain both the varying ICT engagements by firms and the difficulty to copy apparent best practices from other firms. Similarly, Hempell (2002a) finds that complementary innovations are not enough for firms to attain productivity gains from ICT usage. The success of adopting ICT rather depends on a firm's long term innovation strategy and its experience from past innovations in particular. For a representative sample of firms in German distribution and business-related services, the study finds that firms that have introduced process innovations in the past have an output elasticity with respect to ICT capital that is four times as high as in firms without such experience.

\subsection{Empirical Model}

The main question envisaged in this paper is whether firms that introduce new products, introduce new processes or adjust their organisational structure can reap higher benefits from ICT investment than firms that refrain from such complementary efforts. This implies the marginal product of ICT to be higher in innovative firms as compared to the rest of businesses. In order to empirically test this hypothesis, we follow a very similar approach as in Hempell (2002a) and employ an extended Cobb-Douglas function with two types of capital, i.e. ICT capital and non-ICT capital (henceforth entitled as 'other capital') and innovation. In this set-up, the elasticity of output with respect to ICT depends on whether or not the corresponding firm has successfully introduced an innovation:

$$
Y_{i t}=A L_{i t}^{\beta_{1}} K_{i t}^{\beta_{2}+\beta_{5} J_{i}} I C T_{i t}^{\beta_{3}+\beta_{4} \cdot J_{i}} e^{\beta_{6} J_{i}} e^{\eta_{i}+\varepsilon_{i t}}
$$

with $Y_{i t}$ denoting value added of firm $i$ in period $t, L_{i t}$ labour input, $K_{i t}$ non-ICT capital, and $I C T_{i t}$ the amount of ICT capital. $\eta_{i}$ captures unobserved determinants of the productivity of firm $i$ and $\varepsilon_{i t}$ represents normally distributed shocks. $J_{i}$ is a dummy variable that proxies the firm's innovative activities which are assumed to be constant over the time period analysed.

\footnotetext{
${ }^{15}$ See e.g. Bertschek and Fryges (2002).
} 
Subject to various definitions discussed below, $J_{i}$ takes the value one if firm $i$ has been innovating successfully, and zero otherwise. $A$ represents multi factor productivity that is common across firms.

In this specification, innovative activities are assumed to have not only a direct impact on firm productivity ${ }^{16}$ (which is reflected by the coefficient $\beta_{6}$ ) but to have also an indirect effect by impacting the marginal productivities of the capital stocks $I C T$ and $K$. These indirect impacts are captured by the coefficients $\beta_{4}$ and $\beta_{5}$. The main question of interest is whether innovative activities enhance the productivity contributions of ICT $\left(\beta_{4}>0\right)$. Moreover, if this property is a feature that distinguishes ICT from conventional capital $K$, we will expect innovative activities not to affect the marginal product of $\mathrm{K}$, such that $\beta_{5}=0$.

In order to investigate eq. (1) econometrically, we transform it into a linear model by taking logs of both sides. Simple rearranging then yields the empirical model:

$$
\begin{aligned}
y_{i t}= & a+\beta_{1} l_{i t}+\beta_{2} k_{i t}+\beta_{3} i c t_{i t} \\
& +\beta_{4}\left(i c t_{i t} \cdot J_{i}\right)+\beta_{5}\left(k_{i t} \cdot J_{i}\right)+\beta_{6} J_{i}+\eta_{i}+\varepsilon_{i t}
\end{aligned}
$$

where small letters denote the corresponding logarithms.

While the treatment of the inputs $L, I C T$ and $K$ is mainly an issue of correct measurement, ${ }^{17}$ the consideration of firms' innovative activities deserves some more detailed comments. For investigating the sources of complementarities between innovation and ICT, it is important to distinguish various possibilities of how the indicator $J_{i}$ for innovative activities is defined. Following suggestions put forward in the Oslo Manual (OECD/Eurostat 1997), we classify innovations into two types according to the degree to which they are based on technologically new knowledge. A first type (a) entails technologically oriented innovations, like the implementation of technologically new processes or the introduction of technologically new products. By contrast, a second type (b) consists of non-technical innovations in firms, like changes in the organisational structures or new management techniques.

In various specifications of the model, we set $J_{i}$ equal to one if firm $i$ has reported to have introduced innovations according to notion (a) or according to (b). For the case of Germany,

\footnotetext{
${ }^{16}$ Equation 1 can equally be transformed into an equation of labour productivity by dividing both sides by labour input. The only difference of such a transformation is that the new coefficient of labour $\beta_{1}{ }^{*}$ will be reduced by 1 , such that $\beta_{I}^{*}=\beta_{r^{-}}$. All the other coefficients are unaffected by this transformation, such that the results and interpretation are the same. Since the framework of the untransformed production function can be interpreted more easily, we follow the specification pursued in most of the related literature and employ the untransformed production function.
} 
we are also able to further differentiate the technological innovations (a) to whether they are based on the adoption of (i) new processes or (ii) the introduction of new products. On the other hand, for the case of the Netherlands, we have the opportunity to distinguish several types of non-technological innovations (b) like changes in (i) strategy, (ii) marketing, (iii) restructuring and (iv) management.

A further aspect of the exploration concerns the question of whether the continuity of a firm's engagement in innovation is important. The introduction of ICT-based systems may have large impacts on the structure of businesses within firms. Therefore, ICT-investment projects may take longer time periods to be implemented successfully. Moreover, the adoption of ICTbased processes may lead to a whole chain of various subsequent innovations. To improve efficiency in large firms, for example, the standardisation of processes and data formats may lead to sequences of innovations in various parts of an enterprise. Moreover, the successful introduction of new services may require continuous improvements of the products. Therefore, we expect firms that are engaged in ICT more continuously will be able to reap higher productivity gains from cost savings (through better processes) or sales growth (due to better products) than firms that innovate rather occasionally or not at all.

Since we have available data on innovation only from two cross-sections of the Community Innovation Survey (CIS), we distinguish the cases whether firm $i$ has reported a product (or process) innovation in both periods 1994-1996 AND 1996-1998 $\left(J_{i}=1\right)$ or not $\left(J_{i}=0\right)$. The results from this definition will be compared to the outcomes of an alternative, weaker, definition of $J_{i}$ in which $J_{i}=1$ if firm $i$ has reported an innovation in at least one of the periods 1994-96 OR 1996-1998. This distinction between the AND and the OR-definition of $J_{i}$ is supposed to reflect the importance or the sustainability of the corresponding innovation strategy and therefore forms the basis for the regressions conducted for both countries.

\section{Data and summary statistics}

For the subsequent empirical analysis, firm-level data from the Community Innovation Survey (CIS) are employed. The main aim of CIS is to collect representative and internationally comparable firm-level data on technological innovations. The survey resulted from an initiative by the OECD and the European Statistical Office (Eurostat) to formulate guidelines for an internationally comparable questionnaire and methodological design for innovation

\footnotetext{
${ }^{17}$ The measurement of the variables for the empirical analysis is discussed in more detail in the following section.
} 
surveys for its member countries. ${ }^{18}$ In Germany, the survey is conducted annually by the Centre for European Economic Research (ZEW), Mannheim, on behalf of the German ministry for education and research $(\mathrm{bmb}+\mathrm{f}) .{ }^{19}$ In the Netherlands the survey is conducted by Statistics Netherlands.

The harmonised survey of CIS is conducted and evaluated every four years. For our analysis, we employ the second wave of the survey (CIS 2) with data referring to 1996. Moreover, a very similar survey has been repeated in both countries for 1998, such that this wave (denoted as CIS 2.5) is also employed. We restrict the analysis to the service sector. More specifically, we consider business-related and distribution services. The detailed list and classification of the corresponding industries is summarised in Table A2 in the Appendix.

The focus of innovation as defined by CIS is mainly on three characteristics of innovations. The innovation should (1) be based on technological new knowledge, (2) be new or significantly improved to the corresponding firm, ${ }^{20}$ and it should (3) be implemented successfully, either in the form of new (or significantly improved) products or services (product innovations) or new processes (process innovations). The harmonised questionnaire refers to a three-year period such that a firm is designed as an innovator if it has introduced an innovation in the current or one of the two preceding years.

Beyond these data, various more detailed questions are entailed in the individual designs of the CIS questionnaires for Germany and the Netherlands which are not harmonised. For the purpose of our analysis, the Dutch survey covers more detailed information on four types of non-technological innovations (changes in strategy, marketing, restructuring and management), and the German survey allows to distinguish explicitly between product and process innovations. This additional information will be used in more detailed regressions for both countries individually.

The sample of the data for which information from both countries are available covers firms with 5 and more employees. ${ }^{21}$ This censoring thus omits a substantial part of small seized firms, in particular a large fraction of just started new firms which may be important sources of innovation. ${ }^{22}$ However, compared to most related studies that analyse the productivity of ICT at the firm-level and that are mainly focussed on large firms only, the size spectrum entailed in the employed samples is quite broad.

\footnotetext{
${ }^{18}$ See the Oslo-Manual (OECD/Eurostat 1997) that was first published in 1992.

${ }^{19}$ See Janz et al. (2001) for a detailed discussion of the German innovation survey.

${ }^{20}$ This means that product innovations are not necessarily market novelties.

${ }^{21}$ CIS 2 for the Netherlands, however, did not contain firms with 5 to 9 employees.
} 
In order to assess the productivity effects, we employ further data on firms' output, labour input (in full-time equivalents) as well as investments in ICT and non-ICT. In the German innovation survey, this information is covered in the CIS questionnaire. For the Dutch survey, these data are merged from corresponding census data for the period 1993-99. The Dutch data set is based on yearly surveys undertaken by Statistics Netherlands among enterprises with their main activity in the services sector analysed. An important difference between the German and the Dutch sample consists in the coverage of ICT investments. While in the case of the Netherlands, the variable only includes investments in tangible ICT goods, the German survey also includes investments in software. Since software expenditures amount to about 29 $\%$ of total ICT investments in the EU (EITO, 2003), this may lead to substantial differences in the calculated ICT stocks.

\section{Box A: Construction of capital stocks}

An important issue for assessing the productivity effects of ICT concerns the separate construction of capital stocks for ICT capital and conventional (non-ICT) capital from the firm-level investment data. For this purpose, we employ the perpetual inventory method (PIM) as described in Hempell (2002b) and Van Leeuwen and van der Wiel. (2003a). The capital stock $K$ (denoting ICT or non-ICT correspondingly) is assumed to result from investment in the pre-period in the following way:

$K_{t}=(1-\delta) K_{t-1}+I_{t-1}$

where $K$ denotes the real capital stock, $\delta$ is the depreciation rate and $I$ represents investment where prices measured in constant prices. We construct the initial stock for the first period of the sample by assuming constant growth rates of the investment expenditures $g$ during the pre-sample period. As illustrated by Hall and Mairesse (1995), inserting the initial capital stock $K_{0}$ into eq. (A.1), substituting backwards and simplifying terms then leads to:

$K_{0}=I_{0} /(g+\delta)$

Since both the growth rates of ICT investments and its depreciation rates are substantially larger than those of most other capital goods, we construct both stocks of capital in separate exercises. Table 1 summarises the different parameters for capital stocks in both countries. The derivation of the parameters is explained in Hempell (2000b) and van der Wiel (2001a).

\footnotetext{
${ }^{22}$ Although the sample is continuously updated with young firms, those firms will pop up with a certain delay.
} 
For output, we calculate the firms' value added as the difference between sales and intermediate inputs. ${ }^{23}$ All the monetary variables are deflated using corresponding deflators from the statistical offices of Germany and the Netherlands. ${ }^{24}$ Since official statistics tend to understate the true price declines for ICT goods (Hoffmann, 1998), we employ the harmonised price deflators for Germany as proposed by Schreyer (2000). ${ }^{25}$

Since both types of investments (ICT and non-ICT) do not depreciate instantly but rather over years, simple investment data are an unsatisfactory proxy for the capital intensity of firms. To envisage this issue, we take advantage of the longitudinal structure of the data and construct capital stocks (for the beginning of each period) from the corresponding investment data by the perpetual inventory method (See Box A). In our analysis, we thus explicitly take into account potential time lags between the point of time of investments and the time at which the resulting productivity effects show up. ${ }^{26}$ Moreover, ICT capital depreciates faster than nonICT capital, which is reflected by the corresponding depreciation factors.

In the final cleansing of the samples, we had to exclude a variety of firms with item nonresponses or negative value added. Moreover, we restricted the analysis to firms with at least three subsequent observations to enable the application of suited econometric techniques for panel data (see subsequent section). ${ }^{27}$ The resulting samples comprise 995 firms for Germany and 972 firms for the Netherlands.

The corresponding summary statistics reported in Table A1 in the Appendix show that the mean values for inputs and outputs (per employee) are substantially higher for the German samples as compared to the Dutch. Several sources may lead to these extreme differences.

\footnotetext{
${ }^{23}$ Since the intermediate inputs are not available for the German firms, we imputed values by using value addedto-sales shares corresponding industry averages of the shares of value added in sales at the 2-digit NACE as provided by the German statistical office.

${ }^{24}$ These industry-specific deflators are defined at the 2-digit-level for Germany and at a more detailed 3-digitlevel for the Netherlands.

${ }^{25}$ Schreyer (2000) takes the obvious bias of official price indexes into account by calculating a harmonised price index for various OECD countries. He employs official statistics on ICT prices in the U.S., which are based on hedonic techniques, as a reference and assumes that the differences between price changes for ICT and non-ICT capital goods are the same across countries. For the Netherlands, we have also experimented with using a special price index of ICT to deflate the ICT investment series based on information of Statistics Netherlands, with little effects on the results.

${ }^{26}$ Some firms reported a share of ICT investment in total investment expenditures equal to zero for all the periods surveyed. Since the econometric specification is in logs, these firms should be excluded from the full sample. However, it may seem more reasonable to assume that ICT investments in these firms are not zero, in fact, but rather very low and rounded to zero by the respondents. Excluding these firms might lead to an overestimation of the real output contributions of ICT in the economy. Therefore, the ICT stock per worker in firms that reported zero ICT investment was assumed to be equal to the corresponding industry minimum and the corresponding values were imputed.

${ }^{27}$ For the Netherlands, for which more data are at hand, this threshold was raised to 5 subsequent periods to improve the reliability of the calculations of the corresponding capital stocks.
} 
Table 1: Depreciation rates for the German and the Dutch sample

\begin{tabular}{lcccc} 
& \multicolumn{2}{c}{ Annual depreciation rates } & \multicolumn{2}{c}{ Annual growth rates of investments } \\
& Germany & Netherlands & Germany & Netherlands \\
\hline ICT capital & $25 \%$ & $30 \%$ & $40 \%$ & $24,2 \%{ }^{\mathrm{b}}$ \\
non-ICT capital & $6,5 \%$ & $9,0 \%^{\mathrm{a}}$ & $5,0 \%$ & $6,5 \%{ }^{\mathrm{c}}$ \\
\hline
\end{tabular}

${ }^{a}$ unweighted mean of the employed depreciation rates by industries. For the calculation of athe non-ICT capital stocks, data from the German Statistical Office at the NACE two-digit level are employed. For further details, see Hempell (2002b), pp. 7-8.

${ }^{\mathrm{b}}$ unweighted mean of the employed growth rates by industries, consisting of $25 \%$ for wholesale trade, $27,5 \%$ for retail trade and $20 \%$ for other services.

${ }^{\mathrm{c}}$ unweighted mean of the employed growth rates by industries, consisting of $6 \%$ for wholesale and retail trade and $7,5 \%$ for other services.

First, the higher capital intensities for Germany might be due a stronger skewness to the right of the distribution. ${ }^{28}$ Second, as explained above, the measured ICT capital stock for German firms is based on a much broader definition of ICT than in the case of Dutch firms. Third, for both countries, slightly different parameters for growth and depreciation are used for the construction of ICT capital stocks. Fourth, the dissimilarity may also result to some extent from differences in the composition of the sample by industries. For example, the weight of wholesale and retail trade in the Dutch sample is twice as high as in the German sample $(74 \%$ vs. 36\%; compare Table A2 in the Appendix. ${ }^{29}$ These industries are less ICT-capital intensive than other services industries like electronic data processing and technical services.

Table 2 reports some figures on the temporal evolution of ICT intensities over times. For both countries, a strong increase in ICT intensity can be observed, independently from whether ICT intensity is measured as the share of ICT in output or as the share in total capital. This development is due to two sources: First, firms have intensified their spending on ICT. Secondly, the quality of ICT products have increased dramatically which is taken into account by adjusting prices accordingly. Again, as discussed before, the intensities for Germany are substantially higher than those for the Netherlands.

\footnotetext{
${ }^{28}$ The German mean value of firm size (about 292 employees) substantially exceeds the median, which is only 36 employees (not reported). The strong skewness also explains the high standard deviations for Germany. Also in the capital endowments, the mean values for Germany substantially exceed those for the Netherlands. This is mainly due to very capital intensive firms in individual industries, like the rental of buildings. In the econometric analysis, this skewness is ameliorated substantially since the specification is in logarithms.

${ }^{29}$ The difference in sample coverage is partly due to the absence of the majority of 'other Dutch business services' (i.e. SBI 748) in 1999. Part of this branch could not be included since the firm level data of the 1999 survey were considered to be implausible by Statistics Netherlands to be disseminated. For this reason a considerable part of 'other business services' could not be used in this research.
} 
Table 2: Comparison of ICT intensities in the German and the Dutch sample (in constant prices)

\begin{tabular}{lcccc} 
& \multicolumn{2}{c}{ Netherlands } & \multicolumn{2}{c}{ Germany } \\
& 1994 & 1999 & 1994 & 1999 \\
\hline Share of ICT in total capital & 1.5 & 4.6 & 13.1 & 19.1 \\
Share of ICT in value added & 2.1 & 6.0 & 3.2 & 9.7 \\
\hline
\end{tabular}

The figures denote the unweighted averages of the corresponding shares over all firms in the samples.

Finally, Table 3 reports some statistics on the differences between innovative and noninnovative firms. In the reference classification, firms are classified as innovative if they have reported a technological innovation, i.e. a product or process innovations or both, for both the period 1994-96 and the period 1996-98. In the German sample, $18 \%$ of the firms correspond to this definition while the value for the Netherlands is nearly $30 \%$. The discrepancy between the percentages of permanently innovating firms in favour of the Netherlands might be due to the lower share of very small firms (5-9 employees) in the Dutch sample: $6 \%$ versus $18 \%$ in the German sample. It may also be due to methodological reasons: since for Germany an unbalanced panel for 1994-99 is used, some firms may not be covered for both 1996 and 1998.

Table 3: Labour productivity and capital endowment per worker in the German and Dutch samples by innovating and non-innovating firms

\begin{tabular}{rcccc} 
& \multicolumn{2}{c}{ Germany } & \multicolumn{2}{c}{ Netherlands } \\
& Innovators* & others & innovators* & others \\
\hline Share of firms $(\%)$ & $18,0 \%$ & $82,0 \%$ & $29,6 \%$ & $70,4 \%$ \\
value added per employee and year & 125,289 & 140,362 & 61,900 & 52,700 \\
ICT per employees & 5,283 & 3,861 & 2,282 & 1,689 \\
non-ICT per employees & 307,764 & 222,181 & 70,078 & 65,799 \\
\hline
\end{tabular}

* "innovators" refers to firms that have reported process or product innovations (or both) for both the period 1994-96 and the period 1996-98.

Note: Figures refer to the unweighted sample of 995 German and 972 Dutch firms in the service sector. The time periods underlying the averages are 1994-1999 for Germany and 1993-99 for the Netherlands.

Despite these differences in the share of innovators, there is a consistent pattern in the capital intensity for Germany and the Netherlands. The endowment of workplaces with both ICT and non-ICT is substantially higher in innovating firms than in non-innovating ones in both countries. In the Dutch sample, these differences are also reflected in the corresponding numbers for labour productivity which are higher in innovating firms. For Germany, there is a reverse pattern. If, however, one considers the corresponding median values, which are more 
robust to the role of potential outliers, the pattern for German firms corresponds very well to the pattern for Dutch firms as summarised in Table 3.

\section{Empirical results}

In this section we present the main econometric results for the two countries. In order to explore the effect of ICT and innovation on firm performance and the interrelation between innovation and ICT, we estimate our production function model as of equation 2 using the same type of innovation for both countries. Innovation experience in the 'common' model is represented by technical innovation (the implementation of product and/or process innovation) of a more permanent nature. Thus, the dummy variable $J_{i}$ takes on a value of 1 if firms have implemented product and/or process innovation both in period 1994-96 and 199698.

Thereafter, we shift our attention to country-specific models by adapting the 'common model' to the country-specific data on innovation. For Germany this special analysis focuses on the productivity differences between product and process innovations. For the Netherlands the focus is on the different contributions of technical and non-technical innovations to productivity. All models are estimated by using the method of SYS-GMM (see box B).

\subsection{Results for the common specification}

The results for the common specification are presented in table $4 .{ }^{30}$ The coefficients of all three inputs, i.e. labour, ICT capital and non-ICT capital, are significantly different from zero at the one-percent level for the Netherlands. However, although similar in size, the elasticity of ICT capital stocks for Germany, appears to be weakly significant. ${ }^{31}$

By contrast, the labour elasticity obtained for the Dutch sample is much lower than the outcome for Germany. The latter result could be due to the different composition of industries in the panel data for the two countries, already mentioned in section 3. The Dutch panel data contains relatively more wholesale and retail firms that have lower levels of income shares: a rough indicator for the labour elasticity. Another notable difference between the results for

\footnotetext{
${ }^{30}$ For both countries, the regressions also include time dummies and industry dummies. Moreover, the regressions for Germany also take account of a dummy variable for firms located in East Germany.

${ }^{31}$ The lower constant term in the German regressions reflects different scaling of the variables. While German data are in million DM, the Dutch variables are in absolute Euros.
} 
both countries is the implied scale parameter. For Germany we have near constant-returns-toscale, whereas for the Netherlands we found (significantly) decreasing returns-to-scale. ${ }^{32}$

As discussed in earlier sections, ICT opens a variety of innovation potentials. The results reported in Table 4 yield rather convincing evidence for spill-over effects from ICT at the firm level for both countries. ICT use and innovation efforts are complementary as the interaction term $i c t^{*} A N D p d c$ is positive and significant. ${ }^{33}$ This term represents the difference between the elasticities of permanently innovating firms and all other firms. Therefore, the elasticity of permanently innovating firms is approximately $11 \%(=0.022+0.085)$ for Germany and about $9 \%(0.04+0.05)$ for the Netherlands. Thus, the direct contribution of ICT to productivity of permanent innovating firms is twice as much or more (for Germany) as the corresponding value for firms that do not innovate permanently.

\section{Box B: Estimation method}

In this study we use heterogenous firm-level data to investigate the relationship between ICT use, innovation and productivity. It is well-known that the tremendous heterogeneity in performance records at the firm-level can also be attributed to unobservable firm-specific effects. Ignoring these effects may bias OLS estimates severely. The usual approach to circumvent this problem is to eliminate the firm specific parameters by transforming the model into growth-rates and then use the GMM method of estimation. Arellano and Bover (1995) and Blundell and Bond (1998) show that this method may fail in case of weak instruments due to a lack of sufficient correlation between explanatory variables and instruments. To overcome this problem they introduced the method of SYS-GMM. This is a generalized instrumental variables method that uses both the equations in levels and growth rates to account for various sources of estimation biases like measurement errors, reversed causality or endogeneity of explanatory variables. This method is applied in this study.

\footnotetext{
${ }^{32}$ These diverging outcome can mirror different things. Contrary to the Netherlands, the German data may suffer less from selectivity biases as the construction of panel data starts from a more representative sample of firms in the innovation survey. A second (and economic) explanation is that optimal scale sizes in services may show up in the estimate of the scale parameter due to the positive correlation between innovation and firm size (see Van Leeuwen and Van der Wiel (2003b)) .

${ }^{33} A N D p d c$ refers to the dummy variable $J$ of (2). As mentioned, it denotes that firms reported technical innovations in both waves of the innovation surveys. Note that some of them also have adopted non-technical innovations. For the Netherlands, $75 \%$ of firms classified as $A N D p d c$ did also apply non-technical innovations.
} 
Table 4: Results for the ICT - and innovation augmented production function

\begin{tabular}{lcc} 
Production inputs & Netherlands & Germany \\
\hline Constant & $3.904^{* * *}$ & 0.248 \\
& $(0.267)$ & $(0.277)$ \\
Employment $(l)$ & $0.506^{* * *}$ & $0.630^{* * *}$ \\
& $(0.047)$ & $(0.067)$ \\
ICT capital $(i c t)$ & $0.041^{* * *}$ & 0.022 \\
& $(0.009)$ & $(0.027)$ \\
Non-ICT capital $(k)$ & $0.268^{* * *}$ & $0.223^{* * *}$ \\
& $(0.035)$ & $(0.060)$ \\
$i c t^{*} A N D p d c\left(i c t^{*} J\right)$ & $0.047^{* * *}$ & $0.085^{* *}$ \\
& $(0.014)$ & $(0.039)$ \\
$k^{*} A N D p d c\left(k^{*} J\right)$ & -0.022 & 0.022 \\
& $(0.056)$ & $(0.063)$ \\
$A N D p d c(J)$ & 0.146 & 0.160 \\
Industry Dummies & $(0.421)$ & $(0.115)$ \\
Year Dummies & yes & yes \\
R-squared & yes & yes \\
Number of firms & 0.835 & 0.832 \\
Sargan (P-values) & 972 & 995 \\
\hline
\end{tabular}

The dependent variable is value added in constant prices. ANDpdc denotes that firms have implemented product or process innovation during the whole period 1994-1998. The SYS-GMM regressions control for first-and second order correlation of the errors of the model. Heteroscedasticity consistent standard errors are reported in parenthesis. *,**, and *** denote significance at the 10-, 5-, and 1-percent level respectively.

Likewise, we can look at the interaction of innovation and non-ICT capital and compare it ti the interaction with ICT. This comparison yields insights whether ICT is a special type of capital. Once again, we obtain the same results for both countries, indicating that innovation and other capital are not complementary. Indeed, this suggests that ICT is a rather special type of capital in view of its link to innovation.

Finally, we comment on the results for the direct contribution of innovation to Total Factor Productivity (TFP), judged by the estimate of $A N D p d c$. Here, we found that innovation seems to contribute positively to TFP, although for the Netherlands the corresponding estimate is insignificant.

This latter result may be due to various reasons. One possible source may be selectivity. Firms may introduce innovations because they are in economic trouble. In this case, an insignificant direct impact might mirror rather the lower productivity of firms that decide to 
engage in innovations than the effect of the introduction of new processes or products. An alternative explanation might be a more substantial one. The figures for the Netherlands, taken literally, imply that the only productivity gains from innovations in services are attained if they are combined with the simultaneous use of new technologies. Furthermore, there may also be measurement errors that make the estimation of the direct productivity contribution imprecise.

\subsection{Further results for technological innovations in Germany}

A further issue raised in the theoretical part concerns the question whether firms that innovated more continuously than others would also exhibit even higher advantages in productive ICT use than firms that innovated rather occasionally. As already stated in the previous section, the data available for Germany also allow investigating in more detail the link between ICT and innovation considering the type of innovation introduced. The regression results presented in Table 5 shed some light on these issues.

The first specification (ORpdc) of Table 5 uses the same type of innovation as in Table 4, but now a firm is considered as an innovator if it introduced some technological innovation (new processes or products) in at least one of the two periods (1994-96 or 1996-98) considered. The estimate for the interaction term is of the same order of magnitude in this new specification. The same conclusion applies to the innovation contribution to TFP. Thus, using the broadest definition of innovation, there seems to be no additional productivity benefits of innovating more permanently. However, this conclusion changes if we choose a more narrow definition of innovation. Columns 2 and 3 compare the results for product innovations as a special type of innovation. The interaction of product innovation and ICT as well as the innovation impact on TFP become more significant for the firms that implemented new products during the whole period. This finding indicates that a sustained product innovation strategy yields more substantial productivity potentials from ICT usage than just occasional product innovation. The differential in the elasticity of ICT for occasional product innovators $(0,049)$ is less than half as high as for continuous ones $(0,121)$. 
Table 5: Impacts of product and process innovations on the productivity of ICT

\begin{tabular}{lccccc} 
Type of innovation & ORpdc & ANDpd & ORpd & ANDpc & ORpc \\
& $(1)$ & $(2)$ & $(3)$ & $(4)$ & $(5)$ \\
\hline Constant & 0,132 & 0,211 & 0,163 & 0,296 & 0,289 \\
& $(0,299)$ & $(0,296)$ & $(0,308)$ & $(0,312)$ & $(0,296)$ \\
Employment $(l)$ & $0,628^{* * *}$ & $0,641^{* * *}$ & $0,623^{* * *}$ & $0,620^{* * *}$ & $0,604^{* * *}$ \\
& $(0,069)$ & $(0,073)$ & $(0,074)$ & $(0,075)$ & $(0,069)$ \\
ICT-capital $(i c t)$ & $-0,005$ & 0,028 & 0,004 & 0,032 & 0,019 \\
& $(0,035)$ & $(0,027)$ & $(0,034)$ & $(0,026)$ & $(0,032)$ \\
Non-ICT capital $(k)$ & $0,222^{* * *}$ & $0,200^{* * *}$ & $0,244^{* * *}$ & $0,237^{* * *}$ & $0,209^{* * *}$ \\
& $(0,045)$ & $(0,055)$ & $(0,047)$ & $(0,052)$ & $(0,048)$ \\
ict*innovation $\left(i c t^{*} J\right)$ & $0,086^{* *}$ & $0,121^{* * *}$ & 0,049 & $0,118^{*}$ & $0,112^{* * *}$ \\
& $(0,039)$ & $(0,043)$ & $(0,038)$ & $(0,060)$ & $(0,039)$ \\
Innovation & 0,189 & $0,237^{* *}$ & 0,098 & 0,168 & $0,255^{* *}$ \\
& $(0,122)$ & $(0,104)$ & $(0,113)$ & $(0,111)$ & $(0,110)$ \\
& & & & & \\
Sargan & 0,330 & 0,179 & 0,215 & 0,216 & 0,407 \\
R-squared & 0,831 & 0,831 & 0,830 & 0,831 & 0,827 \\
\hline
\end{tabular}

The definition of "innovation"-dummy varies between columns as follows. Innovation is 1 if the corresponding firm has reported technical innovations for at least one of the periods 1994-96 or 1996-98 (ORpdc), a product innovation for both periods (ANDpd), a product innovation in at least one of the periods (ORpd), a process innovation for both periods (ANDpc) and a process innovation in at least one of the periods (ORpc). All estimations are based on two-step SYS-GMM estimator with heteroskedasticity-consistent standard errors and include time and industry dummies. *,**, and *** denote significance at the 10-, 5-, and 1-percent level respectively.

In columns 4 and 5 of Table 5, we compare the results for firms that were engaged in process innovations persistently or occasionally. In both specifications, the interaction terms of ICT and innovation are both significant and quite high at similar levels. This indicates that for long term innovation strategies, the impacts on ICT productivity are quite similar for product and for process innovations.

Summing up the German evidence: the most striking result is that while for continuous process innovators, the productivity gains from ICT are about as high as for occasional ones, continuity in innovations is more important for product innovations than for process innovations. These results indicate that ICT-enabled development of new products calls for a rather long-term innovation strategy.

\subsection{Further results for non-technological innovations in the Netherlands}

Whereas the German CIS survey enables a further breakdown of technical innovation, the Dutch CIS survey allows assessing the impact of non-technical innovations on productivity in 
more detail than the German survey. The Dutch survey distinguishes four types of nontechnical innovations. Besides organisational changes, Statistics Netherlands also differentiates changes in strategy, marketing and management.

Table 6: ICT and non-technical innovations (nti): impact on output for the Netherlands

\begin{tabular}{lccc} 
Type of innovation & ORnti & ANDnti & ANDorg \\
& $(1)$ & $(2)$ & $(5)$ \\
\hline Constant & $4,835^{* * *}$ & $4,935^{* * *}$ & $4,593^{* * *}$ \\
Employment $(l)$ & $(0,293)$ & $(0,299)$ & $(0,273)$ \\
& $0,518^{* * *}$ & $0,464^{* * *}$ & $0,499^{* * *}$ \\
ICT-capital $(i c t)$ & $(0,047)$ & $(0,049)$ & $(0,047)$ \\
& $0,048^{* * *}$ & $0,034^{* * *}$ & $0,046^{* * *}$ \\
Non-ICT capital $(k)$ & $(0,012)$ & $(0,011)$ & $(0,012)$ \\
& $0,151^{* * *}$ & $0,162^{* * *}$ & $0,187^{* * *}$ \\
ict*innovation $(i c t * J)$ & $(0,038)$ & $(0,038)$ & $(0,036)$ \\
& $-0,007$ & $0,040^{* * *}$ & $-0,005$ \\
Innovation & $(0,017)$ & $(0,016)$ & $(0,014)$ \\
& $-0,054$ & 0,036 & $0,143^{*}$ \\
R-squared & $(0,069)$ & $(0,080)$ & $(0,075)$ \\
\% innovators & 0,825 & 0,830 & 0,822 \\
\hline
\end{tabular}

The definition of "innovation"-dummy varies between columns as follows. Innovation is 1 if the corresponding firm has reported non-technical innovations for at least one of the periods 1994-96 or 1996-98 (ORnti), nontechnical innovations for both periods (ANDnti) or organisational changes in both periods (ANDorg). All estimation are based on two-step SYS-GMM estimator with robust standard errors and include time and industy dummies. Sargan tests of the validity of the instruments used are not rejected for all specifications at the $10 \%$ level. *, **, and *** denote significance at the 10-, 5-, and 1-percent level respectively.

Recent Dutch research already pointed towards the importance of non-technical innovations in (business) services. Van der Wiel (2001b) found that firms in Dutch business services that reported non-technical innovations showed higher productivity growth rates than nontechnical innovating firms or firms that reported no innovation at all. This subsection investigates whether this result can be supported after using a regression framework. Table 6 reports the results of this exercise.

Taking the rather broad definition of 'non-technological innovation' into account, it is obvious that certain elements of non-technical innovations also point to the possible emergence of product or process innovation as well. Thus, it should be no surprise that many firms simultaneously applied technical innovations as well as non-technical innovations according to the corresponding definitions (see footnote 33). 
Nevertheless, and similar to technical innovations, firms may also be more or less permanently involved in non-technical innovation. Table 6 clearly points to the benefits of being permanently innovative in a non-technical sense as well (see the column ANDnti of table 7). Following a non-technical innovation strategy on a more continuous basis appears to pay off more than innovating occasionally. Actually, column ANDnti of table 6 is quite similar to the (Dutch) result of table 4, where innovation was defined as the implementation of technical innovations during all years of the period considered. In this respect, the results of table 6 are more distinct from the German sensitivity analysis: for firms that performed nontechnical innovations only incidentally, the interaction of ICT use and non-technical innovations does not lead to higher output growth (compare the ORnti and ANDnti results of Table 6).

Finally, the last column of Table 6 looks at a specific type of non-technical innovation, i.e. organisational changes implemented more continuously. The results show that this type of innovation had a significant and sizeable impact on TFP in Dutch services. Surprisingly, ICT use and organisational changes seem not to be complementary here, as the coefficient of $I C T^{*}$ innovation appears to be insignificant. This contradicts evidence from similar studies for the U.S. (Brynjolfsson et al., 2002). This surprising finding may have something to do with the difficulty to define organisational changes in a strict sense.

\section{Concluding remarks and further research issues}

This paper focuses on the link between ICT use, innovation and business performance in services for Germany and the Netherlands. We adopted an extended production function framework to investigate the link between ICT use and innovation. This framework has been applied to test the hypothesis that firms that introduce new products, new processes or adjust their organisational structure can reap higher benefits from ICT investment than firms that refrain from such complementary efforts. For the empirical implementation of innovation in the model, we employ data from business-related and distribution services obtained from two waves of the Community Innovation Survey (CIS) from both countries.

Although limited to two countries, this comparative study provides important insights in cross-country patterns and differences. The main results of our study can be summarised as follows:

- In both Germany and the Netherlands, ICT capital deepening has raised labour productivity in services firms. 
- For both countries, the results indicate that ICT is used more productively if it is complemented by own innovational efforts in the ICT-using firms. This finding points to spill-over effects from ICT. Moreover, these spill-overs are a particular feature of ICT capital since for non-ICT capital complementarities with innovation are not found.

- For Germany, we find evidence for direct benefits from product and process innovation on total factor productivity (TFP) in services. Firms that innovate permanently show higher TFP levels. This positive direct innovation effect on productivity, however, cannot be found for the Netherlands.

- The results also show that innovating on a more continuous basis seem to pay off more in terms of ICT productivity than innovating occasionally. This effect is found for product innovations (Germany) and non-technical innovations (Netherlands) and to a much smaller extent for process innovations.

As far as economic policy is concerned, the findings of our paper point to the importance of an innovative business environment that is needed to lay the fundamentals for an efficient use of ICT and stimulate productivity growth. For the Netherlands, an acceleration of productivity growth is needed to prevent a substantial decline in GDP growth in the coming years since demographic factors will further slow down labour supply growth.

In particular, rigid labour markets due to both institutional and legislative barriers may hinder firms to re-structure their processes and to adopt new workplace practices and organisational changes that are needed for a productive usage of ICT. In Germany, for example, $9 \%$ of the firms mention internal resistance as a barrier to the adoption of ICT. ${ }^{34}$ Moreover, given that the adoption of ICT is also linked to the invention of new products and services, missing innovation incentives due to the lack of competition may slow down the diffusion of ICT substantially. This is particularly true for the business-related services where the potential for ICT usage is particularly broad while markets are still highly regulated and local. ${ }^{35}$

The approach taken in this study may be extended in various directions in future research. For example, further analysis may focus in more detail on the similarities and differences regarding the construction of the capital variables. Also, potential biases from the lack of output prices at the firm-level may be checked (see e.g. Klette and Griliches, 1996). The most

\footnotetext{
${ }^{34}$ This result is obtained from a representative survey on the diffusion of ICT diffusion among German firms in manufacturing and servicesconducted by ZEW Mannheim among 4450 firms in the fourth quarter of 2002.

${ }^{35}$ Business service markets do not comply with the perfect competition standard set by the welfare theory. Three types of market failures appear to be relevant: failure to account for social externalities, failure due to the existence of market power and failure due to information asymetry (see Kox, 2002).
} 
interesting extension would be to extend the analysis to more countries that have been participating in the Community Innovation Survey. 


\section{References}

Arellano, M. and Bover, O. (1995). Another Look at the Instrumental Variable Estimation of Error-Components Models, Journal of Econometrics 68: 29-51.

Ark, B. van (2001). The Renewal of the Old Economy: An International Comparative Perspective, Technical report, OECD, Paris.

Ark, B. van, Inklaar, R. and McGuckin, R. H. (2002). Changing Gear - Productivity, ICT and Service Industries: Europe and the United States, Paper presented at the ZEW Conference 2002 on the Economics of Information and Communication Technologies, June 24-25, Mannheim.

Bertschek, I. and Fryges, H. (2002). The Adoption of Business-to-Business E-Commerce: Empirical Evidence for German Companies, ZEW Discussion Paper No. 02-05, Centre for European Economic Research.

Blundell, R. and Bond, S. (1998). GMM Estimation with Persistent Panel Data: an Application to Production Functions, Working Paper Series No. W99/4, Institute for Fiscal Studies.

Bresnahan, T. and Greenstein, S. (1996). Technical Progress and Co-invention in Computing and in the Uses of Computers, Brooking Papers on Economic Activity, Microeconomics pp. 1-77.

Bresnahan, T. F. and Trajtenberg, M. (1995). General Purpose Technologies: 'Engines of Growth'?, Journal of Econometrics 65: 83-108.

Bresnahan, T. F., Brynjolfsson, E. and Hitt, L. M. (2002). Information Technology, Workplace Organization, and the Demand for Skilled Labor: Firm-Level Evidence, Quarterly Journal of Economics 117: 339-376.

Brynjolfsson, E. and Hitt, L. M. (1995). Information Technology as a Factor of Production: The Role of Differences Among Firms, Economics of Innovation and New Technology, 3: 193-199.

Brynjolfsson, E. and Hitt, L. M. (2000). Beyond Computation: Information Technology, Organizational Transformation and Business Performance, Journal of Economic Perspectives 14: 23-48.

Brynjolfsson, E., Hitt, L. M. and Yang, S. (2002). Intangible Assets: Computers and Organizational Capital, Brookings Papers on Economic Activity pp. 137-198. 
Colecchia, A. and Schreyer, P. (2001). ICT Investment and Economic Growth in the 1990s: Is the United States a Unique Case?, STI Working Papers 2001/7, OECD.

David, P. (1991). Computer and the Dynamo: The Modern Productivity Paradox in a NotToo-Distant Mirror, in: Technology and Productivity: The Challenge for Economic Policy, OECD, Paris, pp. 315-348.

EITO (2003). European Information Technology Observatory 2003, EITO, Frankfurt/Main.

Hall, B. H. and J. Mairesse (1995), Exploring the relationship between R\&D and productivity in French manufacturing firms, Journal of Econometrics, vol. 65(1), pp 263-293.

Hempell, T. (2002a). Does Experience Matter? Innovation and the Productivity of ICT in German Services, ZEW Discussion Paper 02-43, Centre for European Economic Research. (ftp://ftp.zew.de/pub/zewdocs/dp/dp0243.pdf).

Hempell, T. (2002b). What's Spurious, What's Real? Measuring the Productivity of ICT at the Firm-Level, ZEW Discussion Paper 02-42, Centre for European Economic Research. (ftp://ftp.zew.de/pub/zewdocs/ dp/dp0242.pdf).

Hoffmann, J. (1998). Problems of Inflation Measurement in Germany, Discussion Paper No. 01-98, Economic Research Centre of the Deutsche Bundesbank.

Hollenstein, H. (2002), The Decision to Adopt Information and Communication Technologies (ICT) - Explanation and Policy Conclusions, paper presented at the OECD Workshop on ICT and Business Performance, 9 December 2002, Paris, DSTI/EAS/IND/SWP/AH(2002)2

Janz, N., Ebling, G., Gottschalk, S. and Niggemann, H. (2001). The Mannheim Innovation Panels (MIP and MIP-S) of the Centre for European Economic Research (ZEW), Schmollers Jahrbuch 121: 123-129.

Klette, T.J. and Z. Grilliches (1996), The inconsistency of common scale estimators when output prices are unobserved and endogenous, Journal of Applied Econometrics, vol. 11, p.p. 343-361.

Kox, H.L.M. (2002), Growth challenges for the Dutch business services industry: International comparison and policy issues. $\mathrm{CPB}$, special publication

Leeuwen, G. van, and H.P. van der Wiel (2003a), ICT, innovation and productivity, CPB report 2003/II (forthcoming)

Leeuwen, G. van, and H.P. van der Wiel (2003b), Do ICT-spillovers matters? Empirical evidence for the Netherlands, CPB Discussion Paper (forthcoming)

Licht, G. and Moch, D. (1999). Innovation and Information Technology in Services, Canadian Journal of Economics 32: 363-383. 
OECD (2000a). A New Economy? The Changing Role of Innovation and Information Technology in Growth, OECD, Paris.

OECD (2000b). The Service Economy, Business and Industry Policy Forum Series, STI/OECD.

OECD/Eurostat (1997). Oslo Manual, Proposed Guidelines for Collecting aand Interpreting Technological Innovation Data, OECD/Eurostat, Paris.

Schreyer, P. (2000). The Contribution of Information and Communication Technology to Output Growth: A Study of the G7 Countries, STI Working Paper 2000/2, OECD.

Stiroh, K.J., (2002), Are ICT spillovers driving the New Economy, Review of Income and Wealth, Series 48, Number 1, March 2002.

Wiel, H.P. van der, (2001a), Does ICT boost Dutch productivity growth?, CPB-document no 16.

Wiel, H.P. van der (2001b), Innovation and productivity in services, CPB report 2001/1. 


\section{Appendix}

Table A1: Summary statistics on key variables

\begin{tabular}{|c|c|c|c|}
\hline \multicolumn{4}{|c|}{ Germany } \\
\hline variable & mean* & standard dev.* & mean of values per employee** \\
\hline value added & 36.293 & 332.22 & 137,651 \\
\hline employees & 292.13 & 3855.21 & --- \\
\hline ICT capital & 0.789 & 5.40 & 4,117 \\
\hline non-ICT capital & 34.319 & 176.10 & 237,576 \\
\hline
\end{tabular}

Netherlands

\begin{tabular}{rccc} 
variable & mean* & standard dev.* & mean of values per employee** \\
\hline value added & 7.925 & 21.231 & 58,900 \\
employees & 194 & 682 & --- \\
ICT capital & 0.311 & 1.194 & 1,987 \\
non-ICT capital & 10.456 & 56.336 & 6,7810 \\
\hline
\end{tabular}

* Monetary values in million Euro

** values in Euro

Note: Numbers refer to an unbalanced panel of 995 firms with a total of 4134 observations from the period 199499 for Germany, and a balanced panel of 972 firms with a total of 6804 observations for the Netherlands.

Table A2: Industrial composition of the samples

\begin{tabular}{rccccc} 
& & \multicolumn{2}{c}{ Germany } & \multicolumn{2}{c}{ Netherlands } \\
Industry & NACE-code & \# firms & \% firms & \# firms & \% firms \\
\hline wholesale trade & 51 & 172 & 17,3 & 430 & 44,2 \\
retail trade & 50,52 & 190 & 19,1 & 287 & 29,5 \\
electronic data processing & 72 & 95 & 9,5 & 32 & 3,3 \\
consultancies & $74.1,74.4$ & 103 & 10,4 & 78 & 8,0 \\
technical services & $73,74.2,74.3$ & 143 & 14,4 & 70 & 7,2 \\
other business-related & $70,71,74.5-.8$ & 292 & 29,3 & 75 & 7,7 \\
services & & & & & \\
\hline Total & & 995 & 100 & 972 & 100 \\
\hline
\end{tabular}


Table A3: Composition of samples by firm size

\begin{tabular}{rcccc} 
& \multicolumn{2}{c}{ Germany } & \multicolumn{2}{c}{ Netherlands } \\
size class (\# employees) & \# firms & \% firms & \# firms & \% firms \\
\hline up to 9 & 176 & 17.7 & 58 & 6.0 \\
up to 9 & 176 & 17.7 & 58 & 6.0 \\
10 to 49 & 379 & 38.1 & 238 & 24.5 \\
50 to 99 & 124 & 12.5 & 328 & 33.7 \\
100 to 249 & 162 & 16.3 & 196 & 20.2 \\
250 to 499 & 60 & 6.0 & 94 & 9.7 \\
500 and more & 94 & 9.4 & 58 & 6.0 \\
\hline Total & 995 & 100 & 972 & 100 \\
\hline
\end{tabular}

